\title{
The logging characteristics and evaluation methods of hydrocarbon source rock in coal measures
}

\author{
Pengfei Xin*, Pan Wang,Xiaoting Li \\ State Key Laboratory of Coal Resources and Safe Mining \\ China University of Mining \& Technology (Beijing) \\ Beijing, China \\ 1019083827@qq.com
}

\author{
Yingchuan Sun \\ Liaoning Technical University \\ Liaoning, China
}

\begin{abstract}
Hydrocarbon source rock is the foundation of oil and gas exploration research. At present, geochemical methods are still the mainly used for hydrocarbon source rock studies, which is hard to obtain a continuous data on a single well owing to the limited samples and experimental fees. Logging information has a high vertical resolution and continuous data, and the use of logging characteristics of hydrocarbon source rocks in coal measures provides a new approach in the correct evaluation for hydrocarbon source rocks. Quantitative evaluation and qualitative identification methods of hydrocarbon source rocks in coal measures were introduced, such as cross plot method, $\triangle \log R$ method. The data of TOC by using the methods above is calculated which provides reference for comprehensive evaluation of hydrocarbon source rocks.
\end{abstract}

Keywords-hydrocarbon source rock; geochemical methods; quantitative evaluation; qualitative identification ; TOC

\section{INTRODUCTION}

Correct evaluation of hydrocarbon source rock is the foundation of oil and gas exploration research. In conventional hydrocarbon source rock evaluation, geochemical means are restricted by the costs of drilling and experimental analysis, and limited data obtained cannot give continuous TOC content (TOC) values on a single well. The mean value of the sample data is used to represent the whole of hydrocarbon source TOC values of rock, which will lead to high-quality source rocks segment information being overshadowed by the average $^{[1]}$, and thus cannot reflect the real value of the distribution of total organic carbon, the final evaluation results of hydrocarbon source rock will deviate from the real situation.

Logging can indirectly reflect the lithology and fluid properties, has been quite maturely applied in lithology identification and reservoir evaluation. Special logging response characteristics of source rocks and a high vertical resolution and continuous advantage of logging information will be theoretical basis that the logging and hydrocarbon source rock evaluation are linked together. Combining the logging information and quantitative parameters of source rocks, we can establish appropriate model to calculate the TOC parameters of hydrocarbon source rocks, where TOC parameter has a longitudinally continuous, accurate characteristics. Apply logging evaluation method to TurpanHami Basin Jurassic source rocks on coal.

\section{THEORY AND METHOD}

\section{A. Coal Measures Source Rocks Logging Response Characteristics}

Unique physical and chemical properties of organic matter lead to different responses in the log between the nonhydrocarbon source rocks and hydrocarbon source rocks, which is the physical basis for logging evaluation of source rocks. Coal measures source rocks is one of the main hydrocarbon source rocks, according to the abundance of organic matter from low to high can be divided into mudstone, carbonaceous shale and coal and rock, there are some differences in their logging information. Coal has the performance of "three high three low" logging features, namely high neutron, high acoustic travel time, high resistivity, low density, low natural potential, low natural gamma; carbonaceous shale and mudstone are manifested in high school child high acoustictime, high resistivity, high natural gamma, high uranium content and density logging response characteristics. Unique coal source rocks logging response characteristics make it easier to be distinguished from surrounding rock. Select typical logs of coal measures source rocks to make diagram.

Coal source rock has its unique log response characteristics. Drilling results show, Turpan-Hami Basin has been found its main hydrocarbon source rock reservoir coal source rocks are coal and rock, carbonaceous mudstone and dark mudstone. In order to evaluate the source rocks with logging information, selecting logging data from Hami basin room 1 well, aimed at understanding the correlation between logging information with TOC in coal measures source rocks, providing evidence for the evaluation of follow-up hydrocarbon source rocks.

\section{1) Natural gamma logging feature}

Coal source rocks has a strong adsorption, can absorb radioactive stronger uranium, potassium and other elements, which in the gamma ray log shows high value, easy to distinguish from the surrounding rock. But with the continuous enrichment of organic carbon, source rocks humus 
content decreases, adsorption becomes weaker, decreasing adsorption of radioactive elements, rendering the law of diminishing (Fig.1a) on the gamma ray log value, natural gamma logging values show negative correlation with TOC.

\section{2) Acoustic logging feature}

Organic matter in source rocks is a high acoustic-time substance, causing acoustic logging values significantly higher, much higher than the surrounding rock. Source rocks containing more organic carbon show higher abnormal values in the sonic log. Acoustic logging values are positively correlated with TOC (Fig.1b).

\section{3) Resistivity logging feature}

Belonging to a non-conductive organic material, its positive charge controls the adsorption of other positive ion so as to increase the clay shale rock resistivity. In addition, when mature source rocks, oil and gas generated is stored in the pores fissure, it will also lead to increased resistivity. Therefore, the coal source rocks resistivity will become higher, enriched with organic matter .The values of resistivity logging show positive correlation with TOC (Fig.1c).

\section{4) Density logging feature}

Source rock organic carbon has the characteristics of lightweight, thus the density log values decrease. Coal has the highest organic carbon content in coal source rocks, so coal density is the lowest, followed by carbonaceous shale, mudstone has the higher density ,but lower than the surrounding rock values. The more organic carbon accumulates, the smaller the density $\log$ value is, and density logging is negatively correlated with the value of the TOC (Fig.1d).

\section{B. Qualitative Analsis of Coal Source Rock1 )Curve Method}

Coal measures source rocks in the log showed the "three high three low" characteristics, namely high neutron, high acoustic travel time, high resistivity, low natural potential, low density, low natural gamma. Source rocks rich in organic matter, adsorbing radioactive substances, show high natural gamma; organic light-weight (low-density) results in lowdensity and increased acoustic travel time in hydrocarbon source rock section; source rocks segment relatively rich in hydrogen, perform high value in neutron porosity; poor conductivity kerogen or partial replacement of oil and gas shale skeleton good conductivity and resistivity of the formation water so high. In the logging feature of these coal measures source rocks as the basis, it can be roughly divided into non-hydrocarbon source rocks and hydrocarbon source rocks.

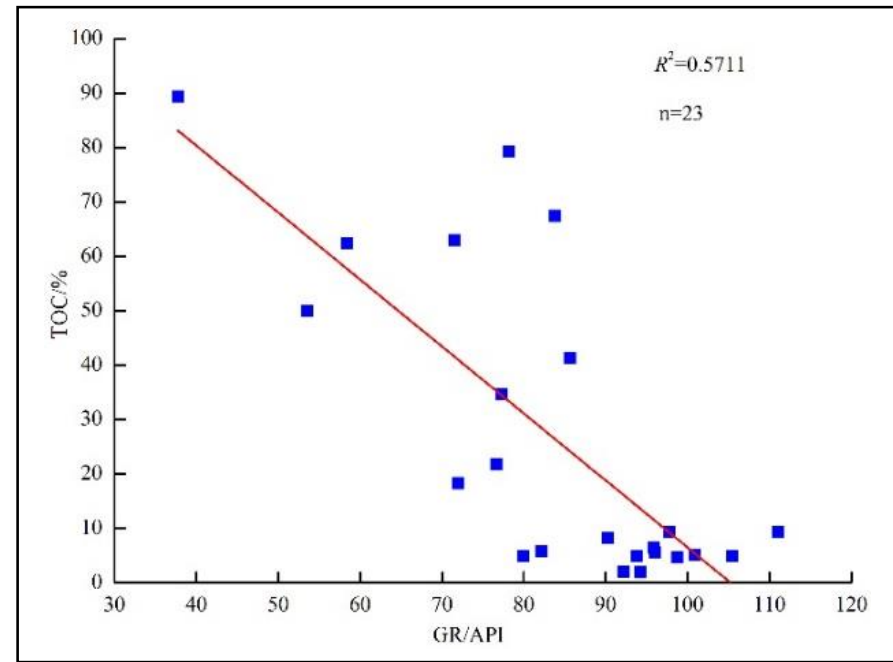

Fig.1a Natural gamma logging values' negative correlation with TOC

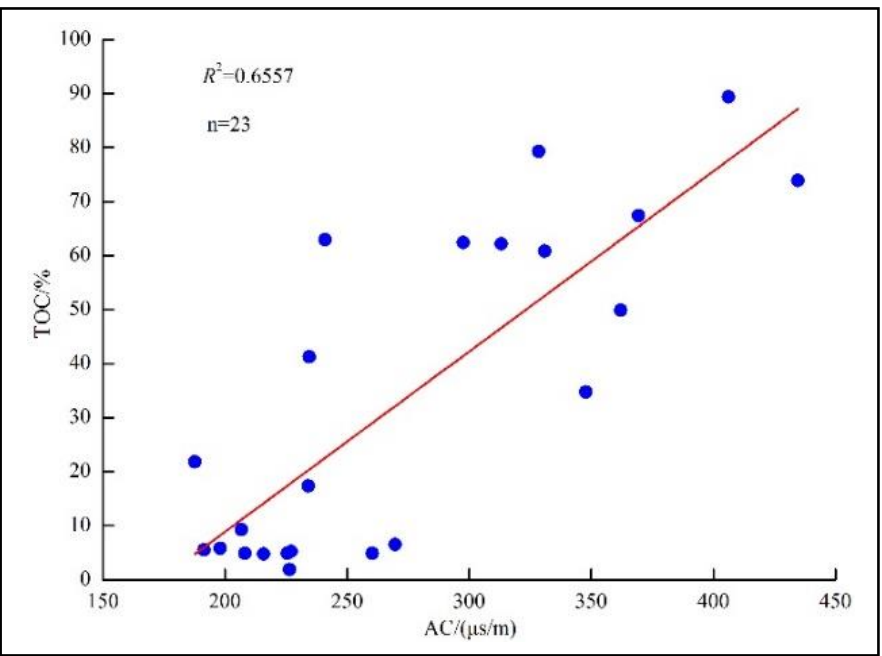

Fig.1b Acoustic logging values' positive correlation with TOC



Fig. 1c Resistivity and TOC relationship 




Fig. 1d Density and TOC relationship

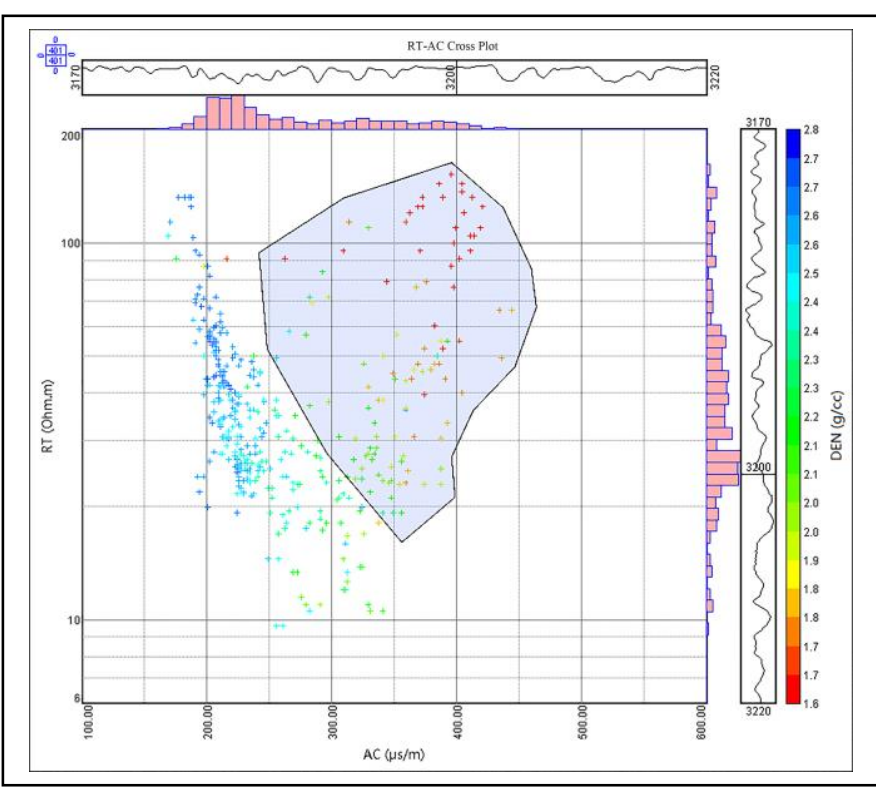

Fig. 2: acoustic-time, resistivity and density logs intersection

\section{2) Cross-plot law}

Choose two or more sensitive response logs of source rocks to do intersection, through distribution of the data points to identify the source rocks ${ }^{[2]}$. Here choose acoustic-time, resistivity and density $\log$ s to do intersection (Fig.2). The points feature of shaded area is as follows: high acoustic-travel time, high resistivity, low density. With fluctuations of the TOC value in coal hydrocarbon source rock, reliability of the method is also constantly changing. For coal and carbonaceous mudstone its credibility is higher ; for mudstone (low TOC content) it is not so reliable.

\section{Coal Measures Source Rocks TOC Logging Quantitative Evaluation Method \\ 1 )Single factor method}

It was found that natural gamma, acoustic time, resistivity, density and neutron logging have good correlation with TOC ${ }^{[3]}$, you can use these logs to get TOC relationship. These relationships can calculate TOC around the entire single well, finally obtain a continuous distribution of TOC values in the longitudinal direction, the coal source rocks Evaluation provides this important parameter TOC. However, such data is only a rough calculation, the correlation is not particularly high, values calculated through the fitting relationship still differ greatly from the actual values.

\section{2) Multi-factor method}

Use statistical method to improve the accuracy of the TOC, we select multiple logging information sensitive to TOC. Compare the calculated precision, thereby screening out an optimal set of regression equations used to calculate the coal measure source rocks TOC, to access to continuous, accurate TOC results.

\section{3) $\triangle \log R$ law}

$\Delta \log \mathrm{R}$ is a new technology, developed by Exxon and Esso in 1979, to estimate ource rocks organic carbon content, can counter the continuous distribution of TOC value ${ }^{[4]}$. The two logs fold (Fig.3).

$\Delta \log \mathrm{R}$ has a linear relationship with the TOC, TOC can be obtained from the relationship. $\Delta \log R$ model obtained by resistivity and acoustic-time superimposed is calculated as:

$$
\Delta \log R=\lg \left(\mathrm{R} / \mathrm{R}_{\text {baseline }}\right)+\mathrm{K}\left(\Delta \mathrm{t}-\Delta \mathrm{t}_{\text {baseline }}\right)
$$

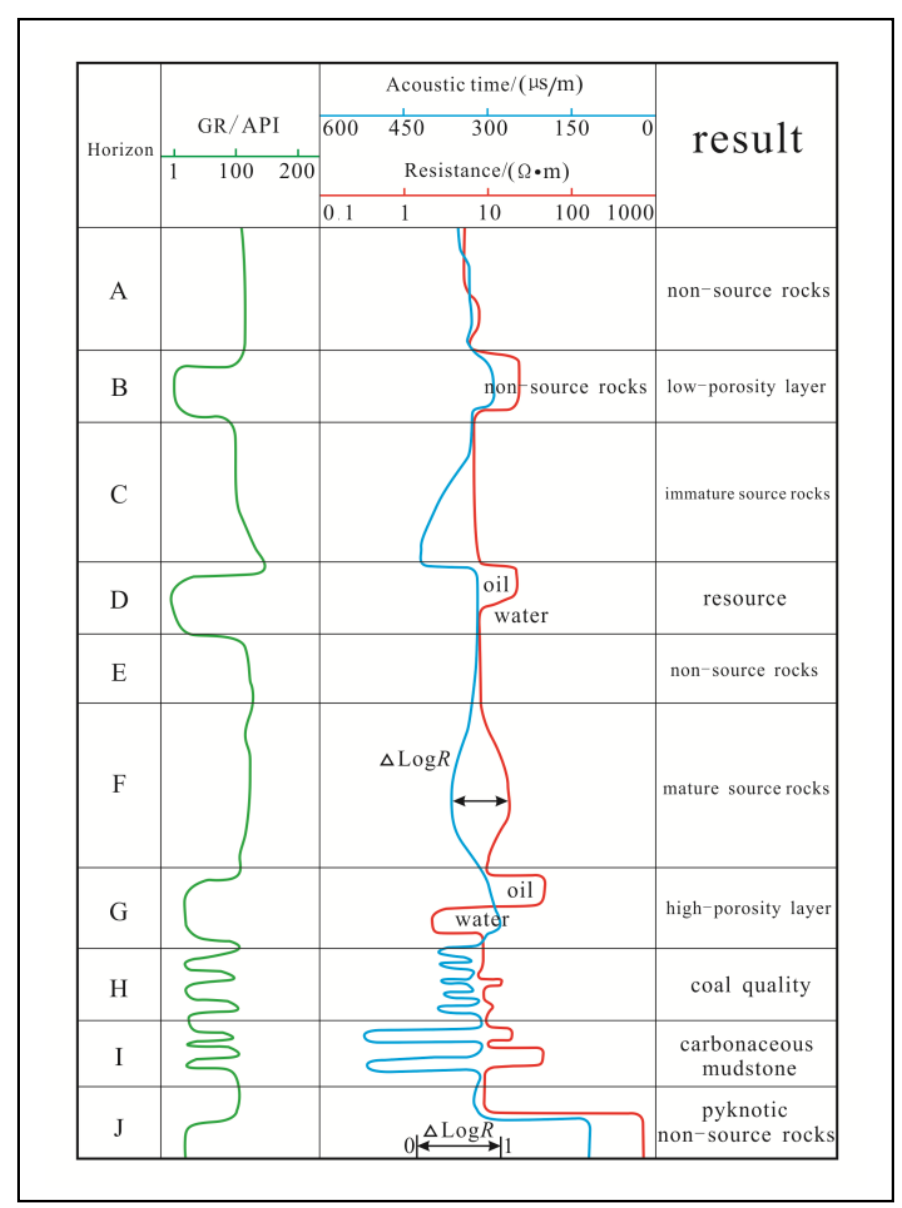

Fig. $3 \Delta \log R$ curves superimposed diagram 
Where, $\Delta \log \mathrm{R}$ is the spacing between resistivity and acoustic travel time curves superimposed after; $\mathrm{R}$ is the measured resistivity $\operatorname{logs}(\Omega \bullet \mathrm{m}) ; \Delta \mathrm{t}$ is the acoustic-time measured $(\mu \mathrm{s} \bullet \mathrm{m}-1) ; \mathrm{R}_{\text {baseline }}$ is the baseline corresponding to resistivity value $(\Omega \cdot \mathrm{m}) ; \Delta \mathrm{t}_{\text {baseline }}$ corresponds to the acoustictime on the baseline $(\mu \mathrm{s} \cdot \mathrm{m}-1) ; \mathrm{K}$ is superposed factor.

Passey et al. after conducting a lot of experiments and statistical analysis, get an empirical formula:

$T O C=\Delta \log R \times 10^{2.297-0.1688 \text { LOM }}+$ TOC $_{\text {background }}$

TOC value of continuous distribution can be calculated through equation (2), which is the thermal index LOM. And the value of TOC background here is needed to be determined. Background values can be measured by non-hydrocarbon source rocks TOC statistical data obtained, LOM can be determined by $\Delta \log$ R-TOC plate method.

\section{EXAMPLES}

Combined with logging data in Turpan-Hami Basin coal strata, the above evaluation methods are used. First, the single well coal source rocks TOC values were calculated, respectively, using a single factor, binary regression curve and $\triangle \log R$ to calculate TOC value in room 1 well (Fig.4), Seen in Fig, these three methods are all given a longitudinally continuous TOC data. Comparatively speaking, the calculation result of a single factor is relatively rough, seen from the correlation analysis of the TOC.

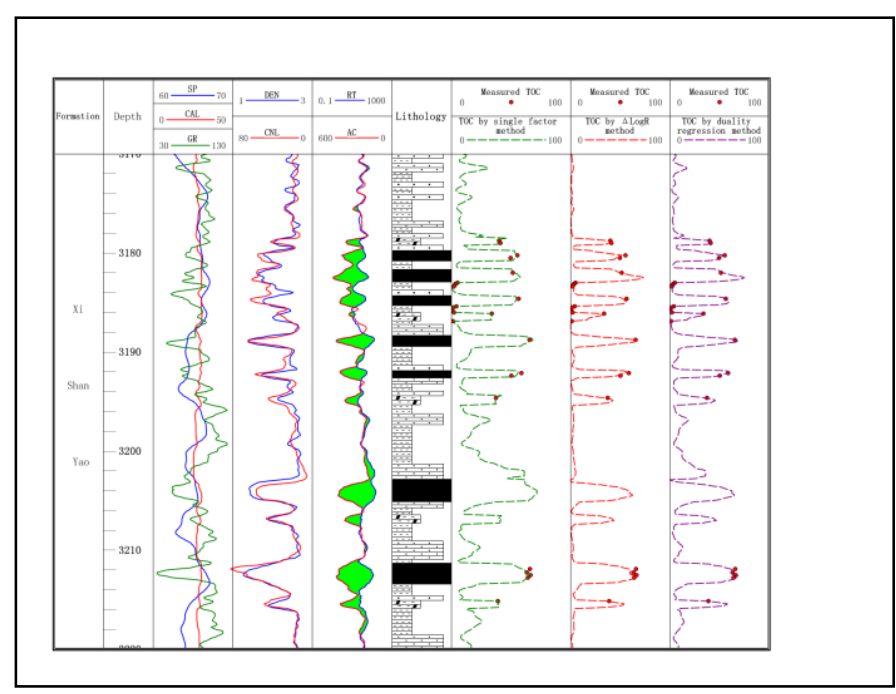

Fig.4 Logging calculated TOC applications in Room 1 well

In order to obtain TOC regional distribution, red table 1 well, red table 3 wells, red table 8 wells, red table 9 wells, Room 1 well and well done big 2 single well are analyzed ,and TOC longitudinal cumulative value per wells are obtained, and finally coal source rocks TOC area contour map is obtained Fig.. 5) by even well analysis. Regional TOC values that warm color is shown in the figure is high, cool color shows low area TOC values. Red table 1 well ,2 wells and the surrounding area have higher TOC values, described as the favorable exploration area and as the region's main oil and gas exploration areas; lower room 1 well and red table 9 wells TOC values are, described as secondary exploration area.

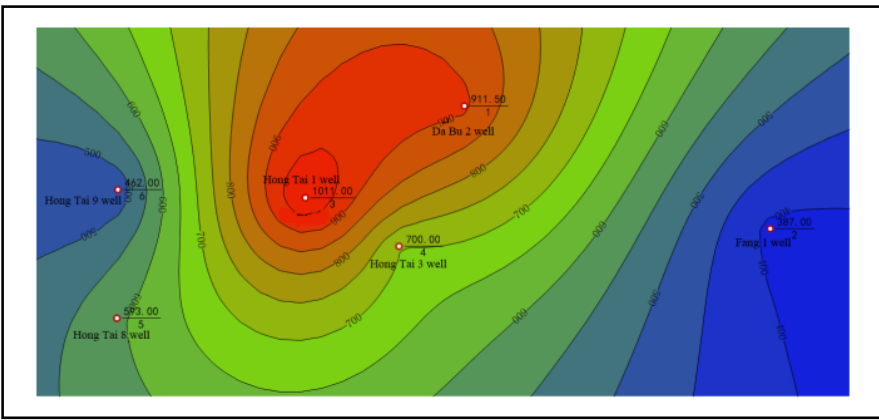

Fig.5 TOC area contour maps3.1 application results in different frequency bands data volume

\section{CONCLUSIONS}

Natural gamma logs, acoustic time, neutron, resistivity and density logs are sensitive to coal source rocks, their response serve as research basis of coal Source Rock Evaluation.

There are variety of source rocks qualitative identification methods, such as law and intersection curves diagram. Curves method used is a single logging information, greater recognition error; relatively speaking, two or two above logs intersection diagram method for coal source rocks pickup is more reliable, as long as the nice logging information selected and good correlation to TOC.

The calculation of organic carbon content is a new method for the evaluation of source rocks, $\Delta \log R$ method is the most practical and the most widely used as a TOC calculation method, it does not require much of the measured data; and Although statistics have great advantages in accuracy, but only if there are some measured TOC data.

\section{References}

[1] H. Amiri Bakhtiar, A. Telmadarreie, M. Shaye Estimating Total Organic Carbon Content and Source Rock Evaluation, Applying $\Delta \log R$ and Neural Network Methods:. Ahwaz and Marun Oilfields, SW of Iran [J] Petroleum Science and Technology,. 2011, 29: 1691-1704.

[2] Schmoker JW, Heater T C. Organic carbon in Bakken formation, united states portion of Williston basin [J]. AAPG bulletin, 1983, 67, 31653174 .

[3] Meyer BL, Nederlof M H. Identification of source rocks on wire line logs by density / resistivity and sonic transit time / resistivity cross-plots [J] AAPG, 1984, 68 (2):. 121- 129.

[4] Passey QR, Creaney S, Kulla JB, et al A practical model for organic richness from porosity and resistivity logs [J] AAPG, 1990, 74 (12):.. 1777-1794. 